\title{
Second Relapse of Pediatric Patients with Acute Myeloid Leukemia: A Report on Current Treatment Strategies and Outcome of the AML-BFM Study Group
}

\author{
Mareike Rasche ${ }^{1, *} \mathbb{0}$, Emma Steidel ${ }^{1}$, Martin Zimmermann ${ }^{2}$, Jean-Pierre Bourquin ${ }^{3}$, Heidrun Boztug ${ }^{4}$, \\ Iveta Janotova ${ }^{5}$, E. Anders Kolb ${ }^{6}$, Thomas Lehrnbecher ${ }^{7}$, Nils von Neuhoff ${ }^{1}{ }^{10}$, Naghmeh Niktoreh ${ }^{1}{ }^{10}$, \\ Nora Mühlegger ${ }^{4}$, Lucie Sramkova ${ }^{5}$, Jan Stary ${ }^{5}$, Christiane Walter ${ }^{1}{ }^{\circledR}$, Ursula Creutzig ${ }^{2}$, Michael Dworzak ${ }^{4}$ and \\ Dirk Reinhardt ${ }^{1}$ (1)
}

Citation: Rasche, M.; Steidel, E.; Zimmermann, M.; Bourquin, J.-P.; Boztug, H.; Janotova, I.; Kolb, E.A.; Lehrnbecher, T.; von Neuhoff, N.; Niktoreh, N.; et al. Second Relapse of Pediatric Patients with Acute Myeloid Leukemia: A Report on Current Treatment Strategies and Outcome of the AML-BFM Study Group. Cancers 2021, 13, 789. https://doi.org/ 10.3390/cancers13040789

Academic Editor: Sarah K. Tasian

Received: 20 January 2021

Accepted: 11 February 2021

Published: 14 February 2021

Publisher's Note: MDPI stays neutral with regard to jurisdictional claims in published maps and institutional affiliations.

Copyright: (c) 2021 by the authors. Licensee MDPI, Basel, Switzerland. This article is an open access article distributed under the terms and conditions of the Creative Commons Attribution (CC BY) license (https:// creativecommons.org/licenses/by/ $4.0 /)$.
1 Department of Pediatric Hematology-Oncology, Pediatrics III, University Hospital of Essen, 45147 Essen, Germany; Emma.Steidel@uk-essen.de (E.S.); Nils.vonNeuhoff@uk-essen.de (N.v.N.); Naghmeh.Niktoreh@uk-essen.de (N.N.); Christiane.Walter2@uk-essen.de (C.W.); Dirk.Reinhardt@uk-essen.de (D.R.)

2 Department of Pediatric Hematology and Oncology, Hannover Medical School, 30625 Hannover, Germany; zimmermann.martin@mh-hannover.de (M.Z.); ucreutzig@onlinehome.de (U.C.)

3 Division of Pediatric Hematology/Oncology, University Children's Hospital Zurich, CH-8032 Zurich, Switzerland; Jean-Pierre.Bourquin@kispi.uzh.ch

4 St Anna Children's Hospital and Children's Cancer Research Institute, Department of Pediatrics, Medical University of Vienna, 1090 Vienna, Austria; heidrun.boztug@stanna.at (H.B.); nora.muehlegger@ccri.at (N.M.); michael.dworzak@stanna.at (M.D.)

5 Department of Pediatric Hematology and Oncology, Second Faculty of Medicine, Charles University and University Hospital Motol, 15006 Prague, Czech Republic; Iveta.Janotova@fnmotol.cz (I.J.); Lucie.Sramkova@fnmotol.cz (L.S.); jan.stary@lfmotol.cuni.cz (J.S.)

6 Nemours/Alfred I. du Pont Hospital for Children, Wilmington, DE 19803, USA; Edward.Kolb@nemours.org 7 Division for Pediatric Hematology and Oncology, Hospital for Children and Adolescents, University Hospital, Goethe University Frankfurt am Main, 60590 Frankfurt, Germany; Thomas.Lehrnbecher@kgu.de

* Correspondence: Mareike.Rasche@uk-essen.de; Tel.: +49(0)201/723-1055

Simple Summary: Children with acute myeloid leukemia (AML) experience high relapse rates of about $30 \%$; still, survival rates following the first relapse are encouraging. Hence, it is critically important to examine the consequences of a second relapse; however, little is known about this subgroup of patients. This retrospective population-based analysis intends to describe response, survival and prognostic factors relevant for the survival of children with second relapse of AML. Treatment approaches include many different therapeutic regimens, including palliation and intensive treatment with curative intent (63\% of the patients). Survival is poor; however, patients who respond to reinduction attempts can be rescued with subsequent hematopoietic stem cell transplantation. We deciphered risk factors, such as short time interval from first to second relapse below one year as being associated with a poor outcome. This analysis will help to improve future international treatment planning and patient care of children with advanced AML.

Abstract: Successful management of relapse is critical to improve outcomes of children with acute myeloid leukemia (AML). We evaluated response, survival and prognostic factors after a second relapse of AML. Among 1222 pediatric patients of the population-based AML-Berlin-FrankfurtMunster (BFM) study group (2004 until 2017), 73 patients met the quality parameters for inclusion in this study. Central review of source documentation warranted the accuracy of reported data. Treatment approaches included palliation in 17 patients $(23 \%)$, intensive therapy with curative intent ( $n=46,63 \%)$ and other regimens $(n=10)$. Twenty-five patients $(35 \%)$ received hematopoietic stem cell transplantation (HSCT), 21 of whom $(88 \%)$ had a prior HSCT. Survival was poor, with a five-year probability of overall survival (pOS) of $15 \pm 4 \%$ and $31 \pm 9 \%$ following HSCT $(n=25)$. Early second relapse (within one year after first relapse) was associated with dismal outcome (pOS $2 \pm 2 \%, n=44$ vs. $33 \pm 9 \%, n=29 ; p<0.0001)$. A third complete remission (CR) is required for survival: $31 \%(n=14)$ of patients with intensive treatment achieved a third CR with a pOS of $36 \pm 13 \%$, while 28 patients 
(62\%) were non-responders (pOS $7 \pm 5 \%$ ). In conclusion, survival is poor but possible, particularly after a late second relapse and an intensive chemotherapy followed by HSCT. This analysis provides a baseline for future treatment planning.

Keywords: acute myeloid leukemia; relapse; childhood acute myeloid leukemia; pediatric; salvage therapy

\section{Introduction}

The prognosis of children with acute myeloid leukemia (AML) has improved significantly over the last decades. Current overall survival rates are approaching $70 \%$ as a result of intensive frontline treatment, aggressive salvage therapy following relapse and improvements in supportive care [1-7].

Despite intensive frontline treatments at maximum doses, which include four to five courses of myelosuppressive chemotherapy or an intensive chemotherapy followed by hematopoietic stem cell transplantation (HSCT) for patients categorized as "high-risk," about $30 \%$ of the patients still relapse $[8,9]$. Facing diminishing returns with further chemotherapy intensification due to toxicity, successful management of relapse is critical to improve outcomes for children with AML while we anticipate the development of new therapies [7,10-13].

Over the past 20 years, improvements in survival rates are mainly attributed to advances in post-relapse therapy [7]. Since 1987, international reports of survival after first relapse demonstrate a considerable improvement in overall survival for patients in first relapse. The five-year probability of overall survival (pOS) after relapse was $21-24 \%$ for patients between 1987 and 1997 [13-15], improving to 37-39\% in recent studies through 2014 [10,16-19].

Since 2009, with the completion of the first international relapse AML phase III study for pediatric patients (AML 2001/01 of the International Berlin-Frankfurt-Munster study group), the recommended treatment approach for first relapse includes an anthracyclinebased re-induction followed by a second cycle of chemotherapy and HSCT. In Europe, FLAG (fludarabine, cytarabine, granulocyte-colony-stimulating factor) with or without liposomal daunorubicin (DNX) followed by a second course with FLAG has been commonly used [10]. However, there are no specific treatment guidelines for patients experiencing a second relapse.

With improved survival after the first relapse event, it is critically important to examine the consequences of a second relapse in more detail. Published phase I/II studies fail to provide information about general survival and prognostic factors in this subgroup of patients $[20,21]$. Herein, we report survival results following second relapse from the AMLBerlin-Frankfurt-Munster (BFM) study group from 2004 until 2017, which represents to our knowledge the largest available dataset for this subgroup of pediatric patients. This detailed retrospective analysis intends to describe post-relapse response, survival and any associated prognostic factors relevant for the survival of children with a second relapse of AML.

\section{Materials and Methods}

\subsection{Patients}

Patients with de novo AML enrolled in Germany, Austria, Czech Republic and Switzerland multicenter trials and population-based registries of the AML-BFM study group between 2004 and 2017 (AML-BFM study 2004-ClinicalTrials.gov Identifier: NCT00111345, AML-BFM registry 2012 and AML-BFM study 2012-EudraCT 2013-000018-39) were reviewed. Included were patients between $0-18$ years at initial diagnosis. The analysis excluded secondary leukemia, Down syndrome myeloid leukemia, mixed phenotype acute leukemia (MPAL) without AML specific treatment and acute promyelocytic leukemia.

Patients less than 22 years of age at second relapse and a documented date of first complete remission (CR1) and CR2 and a date of second relapse between January 2004 and December 2017 were included. We excluded two patients with preceding isolated first CNS 
relapse who did not receive systemic chemotherapy for the first relapse, one patient with an underlying syndrome and one patient with insufficient data (see Figure 1).

Enrollment into AML-BFM study 2004, AML-BFM registry 2012 or AML-BFM study 2012

0-18 years of age at initial diagnosis with de novo AML treated according to AML-BFM protocols

Initial diagnosis from 2004 until 2017

No APL, ML-DS, MDSr-AML, secondary AML, initial isolated myelosarcoma $(n=1222)$

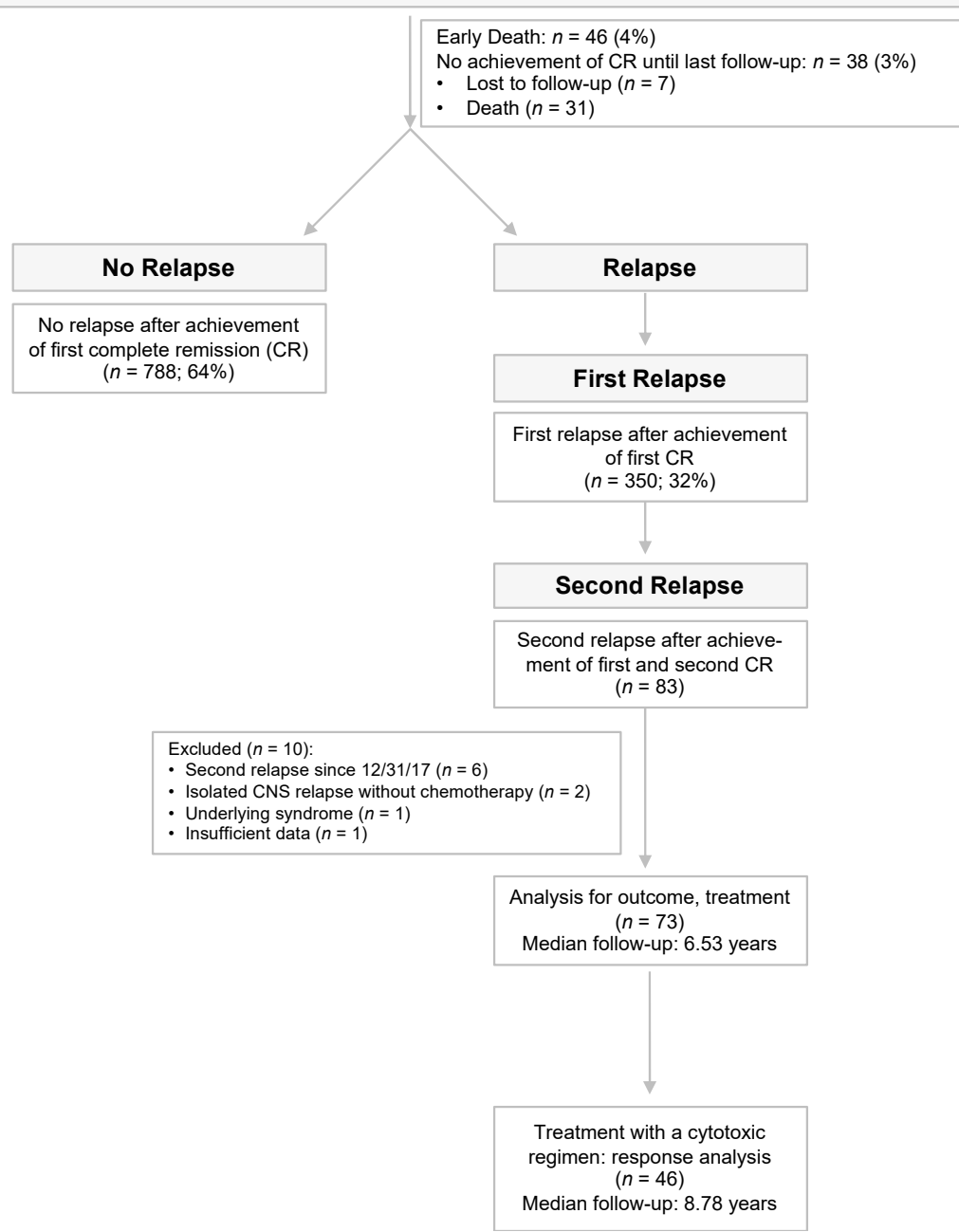

Figure 1. CONSORT diagram. CONSORT flow diagram showing patients of the acute myeloid leukemia- Berlin-Frankfurt-Munster (AML-BFM) studies and registries from 2004 und 2017 that have been included or excluded from the retrospective analysis. Abbreviations: ML-DS, patients with Down syndrome myeloid leukemia; APL, acute promyelocytic leukemia; MDSr-AML, AML with myelodysplasia related changes; CR, complete remission.

\subsection{Previous Treatment Approaches}

Following initial diagnosis, patients were treated on either the randomized phase III studies AML-BFM 2004 and AML-BFM 2012, or the AML-BFM registry 2012 [4]. All studies were performed after approval by national ethics committees and institutional review boards. Following relapse, 39 patients were enrolled on the Relapse AML 2001/01 trial, which recruited patients from November 2001 to April 2009 [10]. After 2009, treatment guidelines (DNX-FLA, FLA and HSCT) were recommended but were not obligatory and institutional standards governed the treatment of patients. In total, 65 of $73(89 \%)$ patients received (DNX)-FLA following their first relapse. 


\subsection{Definitions and Statistical Analysis}

Second relapse was defined as reappearance of leukemic blasts in the peripheral blood, re-infiltration of the bone marrow with $\geq 5 \%$ distinct blasts not to be assigned to any other cause, or distinctive leukemic infiltration elsewhere following CR or partial remission lasting at least four weeks. Reappearance or development of cytologically proven extramedullary disease was considered as relapse. Thus, all patients must have reached two complete remissions before diagnosis of this relapse (CR1 and CR2) (Table S1). Recorded data of the BFM trials and registries including patients with second relapse have been reviewed retrospectively. In addition, medical reports of the treating clinics have been evaluated centrally for detailed information about treatment before and after second relapse, HSCT and cause of deaths. Response assessments following intensive treatment with the intent to induce remission occurred after up to two cycles of treatment. Among 46 patients with intensive treatment, bone marrow response evaluation was available in 45 . In $n=23(51 \%)$ of these patients, a central review was performed in the national reference laboratories of the BFM study group. Response in the remaining $(n=22,49 \%)$ was reviewed at the treating institution. Risk stratification was retrospectively performed for all patients (Table S1).

Statistical analyses were performed with SAS (SAS Institute version 9.4, Cary, NC, USA). All living patients were censored at the time of last follow-up, but not later than 27 March 2020. The median follow-up after diagnosis of second relapse was 6.5 years. Details on definitions are included in Table S1. The Kaplan-Meier method was applied to estimate five-year probabilities of survival and comparisons were performed with the log-rank test. Cumulative incidence functions of early death were constructed according to Kalbfleisch and Prentice. $p$ values $<0.05$ were considered significant.

\section{Results}

\subsection{Patient Characteristics}

Seventy-three patients fulfilled the inclusion criteria of this study (Table 1). The median age at second relapse was 9.2 years: 8.4 years at first relapse and 7.4 years at initial diagnosis. In total, $60 \%(n=44)$ of the patients were male. Forty-four percent $(n=32)$ of patients with second relapse were retrospectively categorized in the "high-risk group" by fulfilling the relevant genetic and response criteria at initial diagnosis. Sixty percent $(n=44)$ of the patients experienced a second relapse within one year after the diagnosis of a first relapse.

\subsection{Treatment}

Eighty-nine percent of the patients with second relapse ( $n=65$ of 73) had received an anthracycline-containing re-induction (DNX-FLA) followed by FLA or another intensive treatment regimen following the first relapse (see Table 1), and $80 \%(n=58)$ and $7 \%$ $(n=5)$ had one or two previous HSCTs, respectively. Two patients had a HSCT during first-line treatment only (Table 1). Five patients received a HSCT twice for first-line and relapse therapy. Nine patients did not have any preceding HSCT (Table 1). In contrast to the standardized treatment approaches in the first relapse, patients with a second relapse received a wide range of therapy. We assigned patients to one of three categories: (1) patients with an intensive treatment approach with the intent to induce remission, (2) patients with palliative treatment, or (3) other treatment approaches (see Table 2).

Of 46 patients $(63 \%)$ receiving intensive systemic therapy, 12 received at least one course of (DNX)-FLA(G) (16\%) (Table 2). Three of those patients received (DNX)-FLA(G) in combination with gemtuzumab ozogamicin, and another three in combination with clofarabine. Twenty patients (27\%) received no (DNX)-FLA(G), but a gemtuzumab- or clofarabine-based treatment. Fourteen additional patients $(19 \%)$ received an intensive treatment approach with the intent to induce remission via other individual approaches with or without subsequent HSCT. Seventeen patients (23\%) received palliation only (Table 2$)$. Thirteen $(76 \%)$ of the patients treated only with palliation experienced a second relapse within a year of the first relapse, and 14 patients (88\%) had a first relapse within a year of diagnosis. Eleven patients $(65 \%)$ had both an early first and early second relapse. 
Table 1. Baseline characteristics.

\begin{tabular}{|c|c|c|c|}
\hline \multicolumn{2}{|c|}{ Characteristics } & \multirow{2}{*}{$\begin{array}{c}\begin{array}{c}\text { Second } \\
\text { Relapse }\end{array} \\
73(100 \%)\end{array}$} & \multirow{2}{*}{$\begin{array}{c}\begin{array}{c}\text { Second Relapse } \\
\text { Intensive Treatment }\end{array} \\
46(100 \%)\end{array}$} \\
\hline Number of patients & $n(\%)$ & & \\
\hline \multicolumn{4}{|c|}{ Initial characteristics } \\
\hline Age & (years), median (range) & $\begin{array}{c}7.4 \\
(0.2-17.8)\end{array}$ & $7.7(0.2-17.8)$ \\
\hline \multirow{2}{*}{ Gender } & Male & $44(60 \%)$ & $28(61 \%)$ \\
\hline & Female & $29(40 \%)$ & $18(39 \%)$ \\
\hline \multirow{7}{*}{ FAB } & M0 & $4(5 \%)$ & $3(7 \%)$ \\
\hline & $\mathrm{M} 1 / \mathrm{M} 2$ & $27(37 \%)$ & $17(37 \%)$ \\
\hline & M4/M5 & $33(45 \%)$ & $21(46 \%)$ \\
\hline & M4eo & $1(1 \%)$ & $1(2 \%)$ \\
\hline & M6 & $2(3 \%)$ & $2(4 \%)$ \\
\hline & M7 & $5(7 \%)$ & $2(4 \%)$ \\
\hline & Non-classified & $1(1 \%)$ & - \\
\hline Blood counts & $\begin{array}{l}\mathrm{WBC}\left(\times 10^{3} / \mathrm{dL}\right) \\
\text { median }(\text { range })\end{array}$ & $\begin{array}{c}13.7 \\
(1.1-331.0)\end{array}$ & $\begin{array}{c}14.9 \\
(1.1-331.0)\end{array}$ \\
\hline \multirow{4}{*}{ Risk group * } & Standard & $6(8 \%)$ & $3(7 \%)$ \\
\hline & Intermediate & $29(40 \%)$ & $18(39 \%)$ \\
\hline & High & $32(44 \%)$ & $23(50 \%)$ \\
\hline & No data & $6(8 \%)$ & $2(4 \%)$ \\
\hline Initial response & $\mathrm{CR}$ & $68(93 \%)$ & $43(94 \%)$ \\
\hline \multicolumn{4}{|c|}{ Previous treatment regimen } \\
\hline \multirow{3}{*}{$\begin{array}{l}\text { Initial treatment } \\
\text { protocol }\end{array}$} & AML-BFM study 2004 & $62(85 \%)$ & $38(83 \%)$ \\
\hline & AML-BFM registry 2012 & $9(12 \%)$ & $6(13 \%)$ \\
\hline & AML-BFM study 2012 & $2(3 \%)$ & $2(4 \%)$ \\
\hline \multirow{4}{*}{$\begin{array}{l}\text { Previous relapse } \\
\text { treatment }\end{array}$} & DNX-FLA(G)+/-FLA(G) & $51(70 \%)$ & $32(70 \%)$ \\
\hline & $\begin{array}{l}\text { DNX-FLA }(\mathrm{G}) \text { + other intensive } \\
\text { regimen ** }\end{array}$ & $14(19 \%)$ & $9(20 \%)$ \\
\hline & Clofarabine-cont. regimen & $2(3 \%)$ & $2(4 \%)$ \\
\hline & Others & $6(8 \%)$ & $3(7 \%)$ \\
\hline \multirow{5}{*}{ Previous HSCT } & No HSCT & $9(12 \%)$ & $7(15 \%)$ \\
\hline & HSCT at initial disease only & $2(3 \%)$ & $1(2 \%)$ \\
\hline & HSCT at first relapse & $56(77 \%)$ & $35(76 \%)$ \\
\hline & $\begin{array}{l}\text { HSCT at initial disease and } \\
\text { relapse }\end{array}$ & $5(7 \%)$ & $3(7 \%)$ \\
\hline & Unknown & $1(1 \%)$ & - \\
\hline \multicolumn{4}{|c|}{ Relapse characteristics } \\
\hline \multirow{4}{*}{ Age } & At first relapse & 8.4 & 8.6 \\
\hline & (years), median (range) & $(0.8-18.9)$ & $(0.8-18.8)$ \\
\hline & At second relapse & 9.2 & 9.5 \\
\hline & (years), median (range) & $(1.6-20.2)$ & $(1.8-20.2)$ \\
\hline \multirow{4}{*}{$\begin{array}{l}\text { Time to subsequent } \\
\text { relapse }\end{array}$} & Early first relapse & $44(60 \%)$ & $26(57 \%)$ \\
\hline & Late first relapse & $29(40 \%)$ & $20(44 \%)$ \\
\hline & Early second relapse & $44(60 \%)$ & $24(52 \%)$ \\
\hline & Late second relapse & $29(40 \%)$ & $22(48 \%)$ \\
\hline
\end{tabular}

* Patients of the AML-BFM study group have been categorized according to the current risk group definition of the last AML-BFM Study (AML-BFM study 2012). It was used prospectively in the AML-BFM registry 2012 and study 2012, while previous patients were analyzed retrospectively for this purpose. Abbreviations: ${ }^{* *}$ All patients have been treated with at least gemtuzumab ozogamicin or clofarabine after DNX-FLA $(G)$. WBC, white blood cells at initial diagnosis; CR, complete remission at initial diagnosis; DNX, liposomal daunorubicin; FLA(G), fludarabine, cytarabine and granulocyte colony-stimulating factor; HSCT, hematopoietic stem cell transplantation; $\mathrm{FAB}$, French-American-British classification at initial diagnosis. 
Table 2. Treatment and response.

\begin{tabular}{|c|c|c|}
\hline \multicolumn{2}{|r|}{ Second Relapse Treatment and Response of Pediatric AML } & \multirow{2}{*}{$\begin{array}{c}\text { Patients (\%) } \\
73(100 \%)\end{array}$} \\
\hline & & \\
\hline Chemotherapy * & $\begin{array}{l}\text { Intensive treatment with the intent to induce remission } \\
\text { - Re-induction including (DNX)-FLA }(\mathrm{G})+/ \text {-FLA }(\mathrm{G}) \\
\text { - Additional treatment including GO } \\
\text { - Additional treatment including clofarabine } \\
\text { - Re-Induction including clofarabine or GO, no (DNX)-FLA(G) } \\
\text { - Individual approaches } \\
\text { Others (including withdrawal immunosuppression, DLI or direct HSCT) } \\
\text { Palliative care }\end{array}$ & $\begin{array}{l}46(63 \%) \\
12(16 \%) \\
3 \\
3 \\
20(27 \%) \\
14(19 \%) \\
10(14 \%) \\
17(23 \%)\end{array}$ \\
\hline HSCT & $\begin{array}{l}\text { No HSCT } \\
\text { HSCT } \\
\quad \text { - First HSCT } \\
\quad \text { Second HSCT } \\
\quad \text { - Third HSCT } \\
\quad \text { Unknown } \\
\text { Unknown }\end{array}$ & $\begin{array}{l}47^{+}(65 \%) \\
25(35 \%) \\
2(8 \%) \\
21(88 \%) \\
1(4 \%) \\
1 \\
1\end{array}$ \\
\hline $\begin{array}{l}\text { Response after intensive } \\
\text { treatment }\end{array}$ & $\begin{array}{l}\text { Response evaluation available after up to two cycles of therapy } \\
\text { - CR } \\
\text { - NEL without peripheral regeneration } \\
\text { - NR } \\
\text { Response evaluation available at the end of treatment including HSCT } \\
\text { - CR } \\
\text { - NEL without peripheral regeneration } \\
\text { - NR }\end{array}$ & $\begin{array}{l}45(98 \%) \\
14(31 \%) \\
3(7 \%) \\
28(62 \%) \\
46(100 \%) \\
19(41 \%) \\
2(4 \%) \\
25(54 \%)\end{array}$ \\
\hline
\end{tabular}

* Several patients were treated with diverse combinations. For details see results section. ${ }^{\dagger}$ Including one patient who has been transplanted at the third and one patient at the third and fourth relapse only. Abbreviations: DNX, liposomal daunorubicin; FLA(G), fludarabine, cytarabine and granulocyte colony-stimulating factor; GO, gemtuzumab ozogamicin; DLI, donor lymphocyte infusion; HSCT, hematopoietic stem cell transplantation; NR, nonresponse; CR, complete remission; NEL, no evidence of leukemic blasts, but missing peripheral regeneration. For categories including patients with unknown status, percentages are calculated without "unknown".

The treatment of ten patients was classified as "other": this category included patients who proceeded directly to HSCT $(n=6,8 \%)$, two patients with therapeutic withdrawal of immunosuppression $(3 \%)$, one patient who received donor-lymphocyte infusions (DLI) with radiation therapy $(1 \%)$ and one patient treated via an individual approach with blinatumomab and sorafenib. This patient had MPAL treated according to AML-BFM protocols at initial disease and relapse, but received blinatumomab due to CD19 co-expression at second relapse.

In total, 35\% $(n=25)$ of all patients proceeded to HSCT; in $88 \%(n=21)$ this was a second HSCT (see Table 2).

\subsection{Survival}

Survival after second relapse was poor, with a five-year pOS of $15 \pm 4 \%$ (see Figure $2 \mathrm{~A}$ ) and a considerable cumulative incidence of early deaths (ED) within the first 56 days after diagnosis of second relapse (cumulative incidence of ED $19 \pm 5 \%$ ). Survival did not improve over time from 2004 to 2017 (see Figure 2B).

As described, patients were treated heterogeneously with approaches including palliation, withdrawal of immunosuppression and several different cytotoxic regimens followed by HSCT. Patients who received an intensive treatment approach achieved a five-year pOS of $17 \pm 6 \%$, which rendered a similar outcome as other individualized treatment approaches (n.s.) (see Figure 2C). The median time to death in patients with palliative care was 0.17 years (range 0 to 0.7 ). 
A

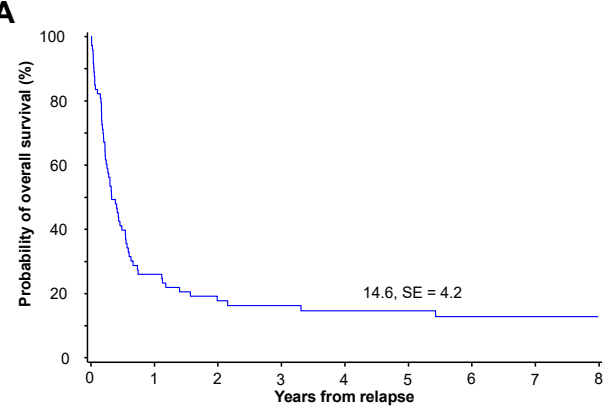

- All Patients ( $n=73,63$ events)

C

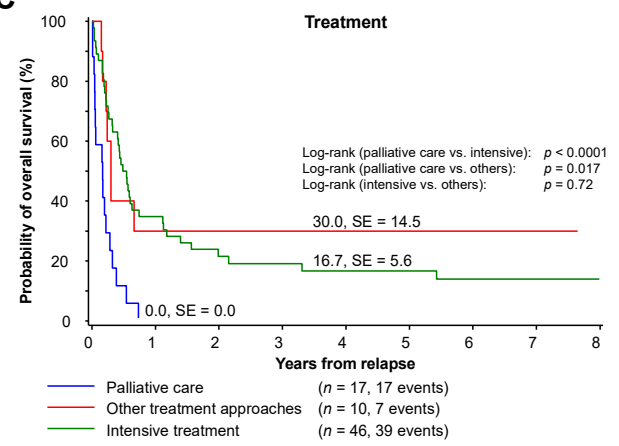

E

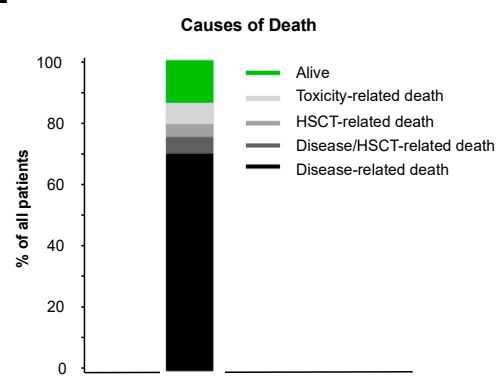

B

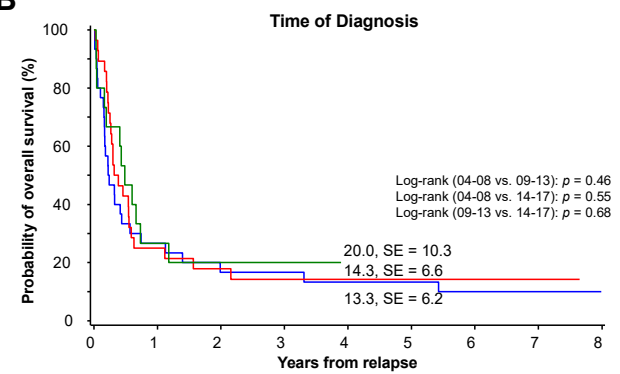

- Second relapse 2004-2008 ( $n=30,27$ events) - Second relapse 2009-2013 ( $n=28,24$ events)

D

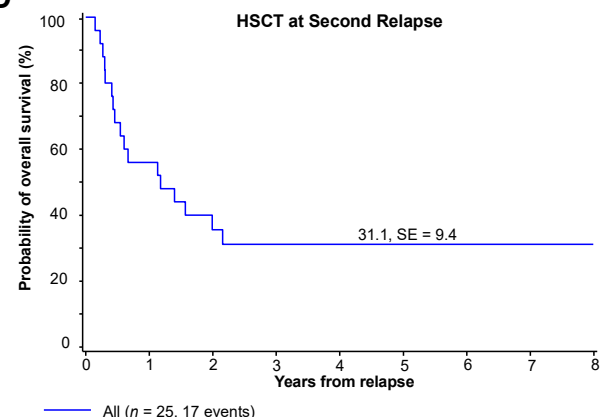

Figure 2. Survival, causes of death and treatment. (A) Five-year overall survival in patients with second relapse of pediatric AML diagnosed from 2004 until 2017. (B) Five-year overall survival in patients with second relapse of pediatric AML grouped by the time of diagnosis. (C) Five-year overall survival in patients with second relapse based on the respective treatment regimen. (D) Five-year overall survival of all patients with HSCT after second relapse. (E) Cause of death in patients with second relapse classified as disease-related, HSCT-related, toxicity-related or combined causes of death. Abbreviations: HSCT, hematopoietic stem cell transplantation.

The survival of the 25 patients who received a HSCT was $31 \pm 9 \%$ (see Figure 2D). Causes of death following a second relapse included disease progression $(n=51,70 \%$ of all patients), a combined HSCT-related and disease-related cause $(n=3,5 \%)$ and HSCT-related complications $(n=4,4 \%)$ or treatment-associated toxicity $(n=5,7 \%)$ (see Figure $2 \mathrm{E})$. All ten patients who survived the second relapse previously received DNX-FLA and HSCT after first relapse, but did not receive a HSCT during first-line treatment. In summary, eight of the surviving patients were transplanted at the second relapse. Four of them achieved CR at second relapse before a second HSCT, whereas three were aplastic with no evidence of leukemic blasts before HSCT, achieving a CR only after HSCT. One patient was transplanted with evidence of blasts and received a treatment with sorafenib and DLI afterwards. The remaining two patients without HSCT at second relapse received DLI in combination with other therapies, including one patient who was transplanted subsequently following a third relapse. 


\subsection{Prognostic Factors}

Probability of five-year survival was $2 \pm 2 \%$ for patients with an early second relapse (defined as a second relapse within one year after first relapse) vs. $33 \pm 9 \%$ for those experiencing a second relapse more than one year after the first $(p<0.0001$; Figure 3A). The time to first relapse did not influence the outcome after second relapse (pOS $14 \pm 5 \%$ vs. $16 \pm 7 \%, p=0.098$; Figure $3 \mathrm{~B}$ ). Survival of patients with high-risk (HR) AML at initial diagnosis was significantly lower compared to intermediate risk (IR) patients (HR $9 \pm 5 \%$ vs. IR: pOS $22 \pm 8 \%, p=0.022$; Figure 3 C). Notably, all patients with standard risk $(n=6)$ had an early second relapse and a pOS of $0 \pm 0 \%$ (Figure $3 C$ ). Age at second relapse $(<2$, $2-9,10-13$ and $>13$ years) did not show any influence on overall survival (Figure 3D). The pOS was $19 \pm 5 \%$ for patients with a prior HSCT at first relapse. Patients without any preceding HSCT $(n=9)$, a HSCT during first-line treatment only $(n=2)$ or a HSCT twice for first-line and relapse therapy $(n=5)$ had a pOS of $0 \pm 0 \%$ (Table 1 ).

\subsection{Patients Receiving an Intensive Treatment with the Intent to Induce Remission}

All patients receiving intensive systemic treatment with curative intent following a second relapse were analyzed separately (see details in results section "treatment"). As demonstrated in Figure 4A, there was no improvement in survival following therapy for patients with a second relapse of AML treated between 2004 and 2017.

A

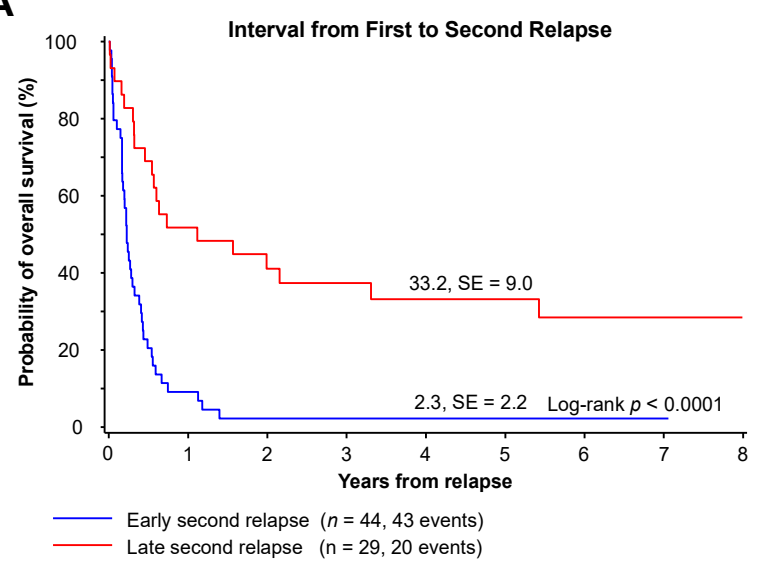

C

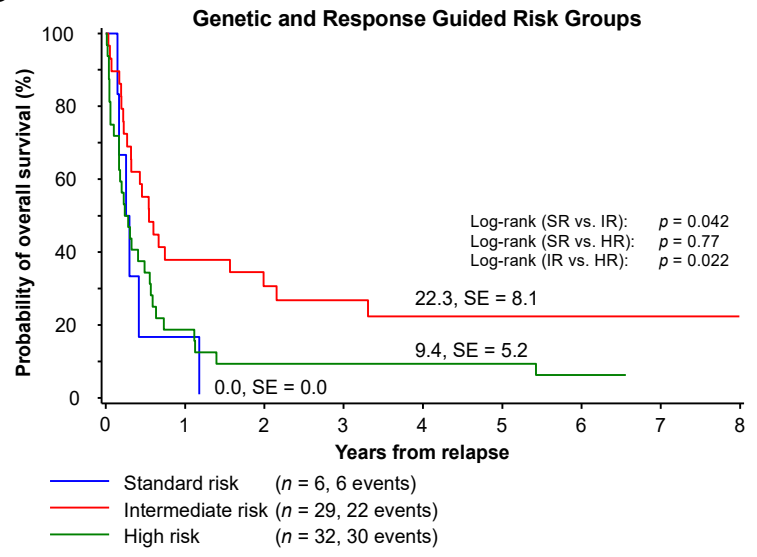

B

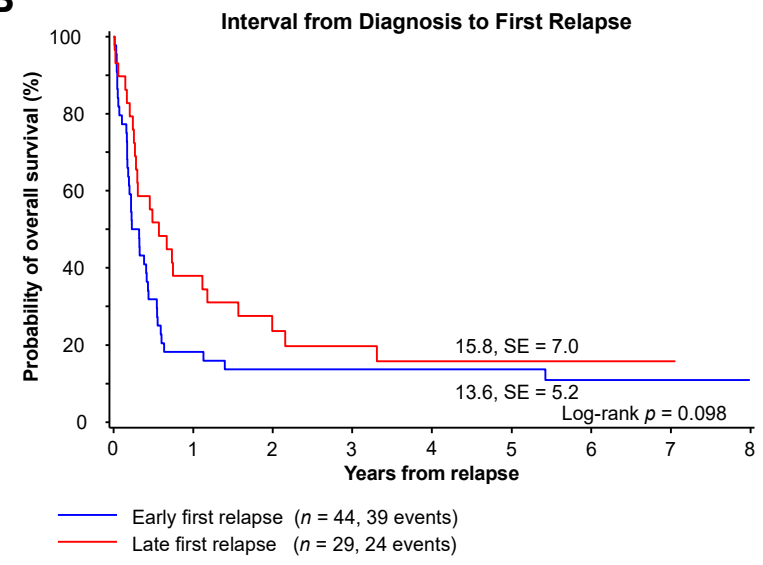

D

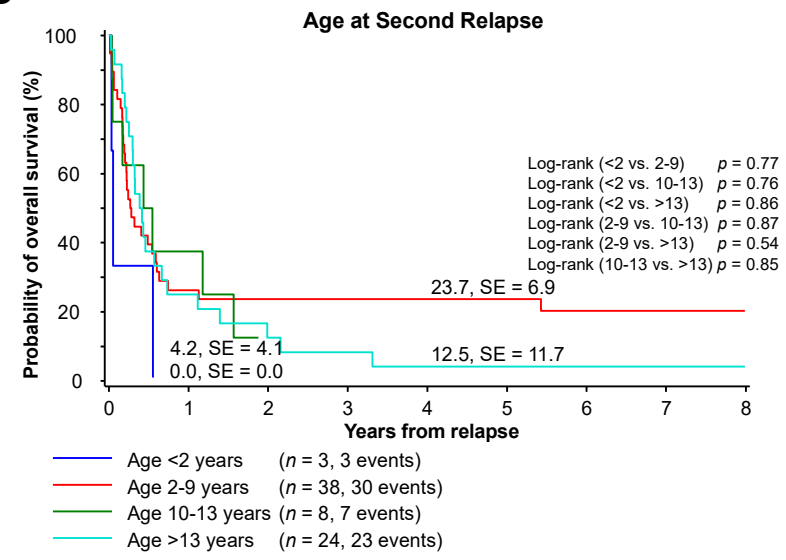

Figure 3. Prognostic factors. (A) Five-year overall survival of patients with early or late second relapse defined as relapse within or after one year after first relapse. (B) Five-year overall survival of patients with preceding early or late first relapse, defined as first relapse within or after one year after initial diagnosis. (C) Five-year overall survival of patients grouped by genetically and response-guided defined risk groups at initial disease. (D) Five-year overall survival of patients grouped by age at second relapse. 
A

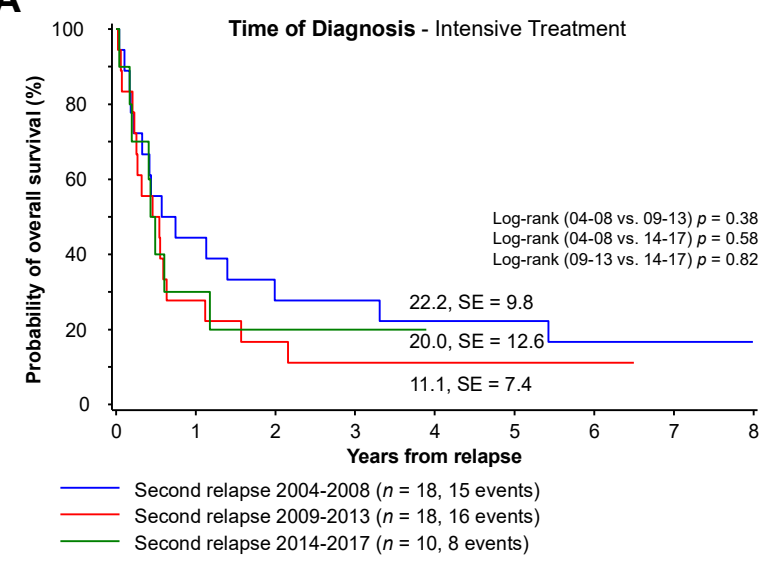

C

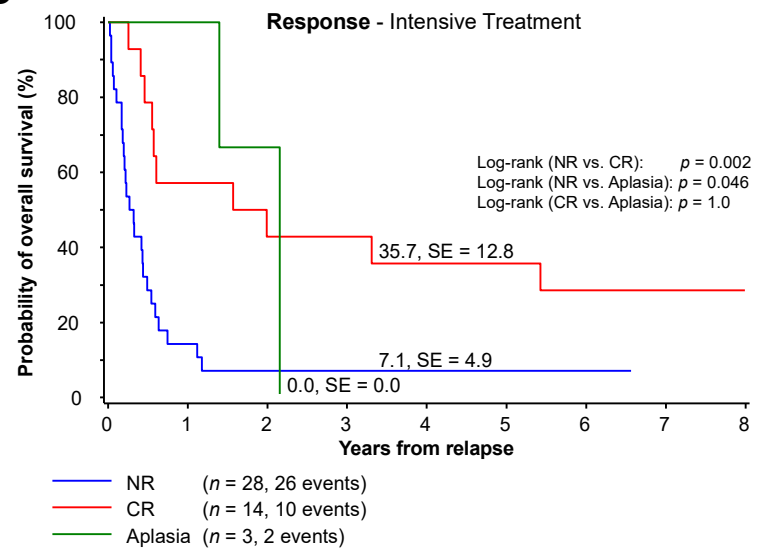

B

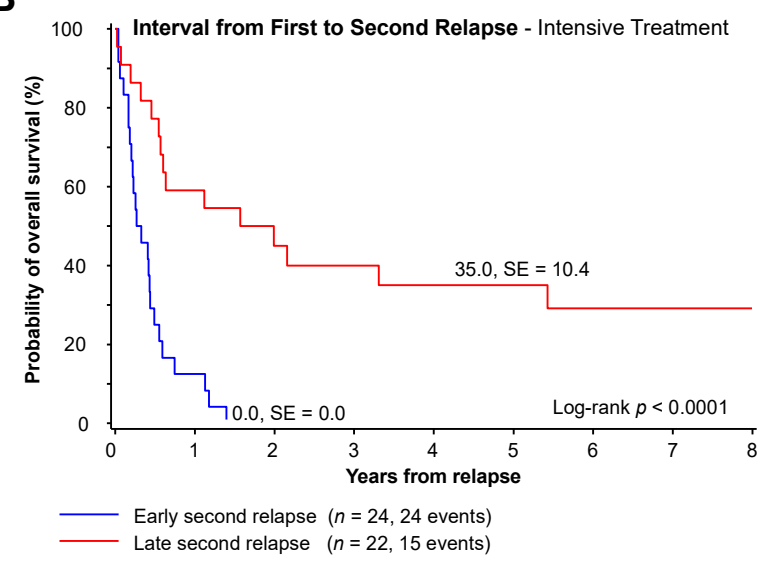

D

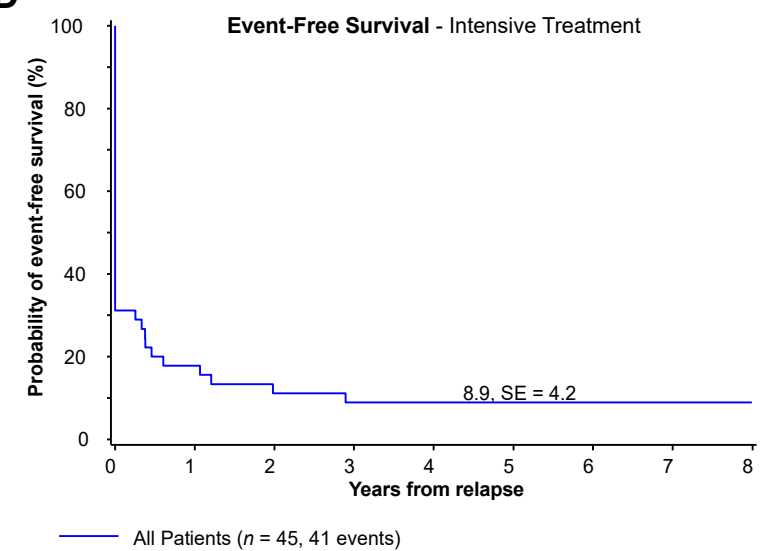

Figure 4. Patients receiving intensive treatment. (A) Five-year overall survival in patients with diagnosed second relapse of AML from 2004 until 2017 and treated with intensive treatment grouped by time of diagnosis. (B) Five-year overall survival of patients with intensive treatment with early or late second relapse defined as relapse within or after one year after first relapse. (C) Five-year overall survival of patients treated with intensive treatment based on the response status after up to two cycles of treatment. (D) Five-year event-free survival of patients treated with intensive treatment. Abbreviations: HSCT, hematopoietic stem cell transplantation; NR, nonresponse; CR, complete remission; Aplasia, no evidence of blasts, but missing peripheral regeneration.

Early second relapse remains a predictor of poor survival (Figure 4B). Risk groups did not reach significance within this smaller subgroup of patients (HR: $13 \pm 7 \%$ vs. IR: pOS $19 \pm 10 \%, p=0.11)$.

Forty-five of 46 patients had a best bone marrow response reported for up to two cycles of re-induction therapy. Nearly a third $(31 \%, n=14)$ achieved a third CR with a pOS of $36 \pm 13 \%$, while $62 \%$ of the patients showed either a nonresponse ( $n=28$, pOS $7 \pm 5 \%)$ or no evidence of leukemia with marrow aplasia $(7 \%, n=3$, pOS $0 \pm 0 \%$; see Figure $4 \mathrm{C}$ and Table 2).

Eighteen patients (39\%) out of all 46 receiving intensive third-line treatment proceeded to HSCT. Bone marrow response prior to HSCT was available in 17 patients. The pOS of eight patients who achieved a CR prior to HSCT was $38 \pm 17 \%$, and $44 \pm 22 \%$ for the six patients with NEL/aplasia prior to HSCT. None of the three patients with a nonresponse prior to HSCT survived.

In summary, the event-free survival of the 45 evaluable patients was $9 \pm 4 \%$ at five years (Figure 4D). Despite intensive therapy, 27 patients never achieved a CR, including 25 (54\%) patients with continuous blast persistence (pOS $0 \pm 0 \%$ ) and two patients $(4 \%)$ who 
continued without visible leukemic blasts and never showed regeneration (pOS $0 \pm 0 \%$, see Table 2).

\section{Discussion}

This large retrospective trial confirms that the prognosis of pediatric patients with second relapse of AML remains poor, with a five-year pOS of $15 \%$. Despite encouraging improvements in survival among pediatric patients with AML in the first relapse $[10,11,13-17,19,22,23]$, prognosis of pediatric patients with a second relapse of AML has improved little since 2004. Standardized intensive treatment regimens following an initial relapse yield consistent responses and toxicities, while for patients with a second relapse no general guidelines or trials are available [7]. The development of tolerable and standard regimens for children with a second or greater relapse are needed, as is an international platform for the evaluation of novel therapies.

Patients in second relapse have been heavily pre-treated with several intensive regimens, including at least one HSCT in almost all patients. In this retrospective cohort, therapy following a second relapse included many possible regimens, reflecting the absence of a reliable and effective standard. Intensive therapy including HSCT is required for most patients after a second relapse treated with a curative intent.

Several prognostic factors are described for patients with first relapse: early treatment response and favorable cytogenetics predict a more beneficial outcome, while an early first relapse, specific molecular high-risk alterations, as well as intense first-line postremission therapy (HSCT in CR1) translate into poor survival [10,11,14-16,19,23-27]. To our knowledge, this report provides the first analysis of potential risk factors at second relapse of pediatric AML. Our data indicate that the interval between the first and second relapse and the response status after treatment and particularly before HSCT have an impact on survival after second relapse. In accordance with previously discussed data on first relapse [14-16,19,23,25], we confirmed that a short interval between first and second relapse predicts a poor outcome. This finding underlines the recently published reports that the interval between first HSCT and relapse predicts survival [28]. In our cohort, the interval between diagnosis and first relapse did not impact survival after a second relapse. Remission status following a second relapse and prior to HSCT predicts survival following second relapse. As described for patients with first relapse and patients with relapse after HSCT $[7,10,19,28-31]$, a subsequent HSCT for patients with a second relapse is required for survival.

Our study did not have a sufficient number of patients to identify cytogenetic or molecular subgroup association with survival following a second relapse. However, the features associated with poor survival after second relapse include a poor treatment response at initial diagnosis combined with genetic high-risk features. Nonetheless, for patients receiving intensive systemic therapy following a second relapse, the combined risk stratification did not reach significance. This is contradictory to what is observed in patients following a first relapse, which may be explained by low patient numbers $[10,11,24]$.

Intense first-line post-remission therapy incorporating HSCT in CR1 has been associated with lower remission and survival rates after first relapse when compared to patients treated with chemotherapy alone [11,13]. Interestingly, a previous HSCT did not impair survival in this analysis of survival following a second relapse.

It is important to consider that patients with second relapse are mainly treated individually and are not included in any clinical trials. Therefore, no systematic data highlighting treatment approaches, response or outcomes exists in the field of pediatric AML. Therefore, it will be crucial for future trials to include a consideration of treatment response. Even though some patients with second relapse are included in several pediatric phase I/II trials, the comparison of response rates is only possible to a limited extent due to the merging of several different refractory disease statuses or the combination with other entities (such as acute lymphoblastic leukemia) in these trials, and the low number of patients included 
per trial $[20,21,29]$. Within our subgroup of patients who have been treated with up to two cycles of intensive treatment, the CR rate was $31 \%$.

In a retrospective single-center study in 2000 on adult AML, Stoiser et al. analyzed the prognosis of patients with a second relapse and discussed prognostic factors in these intensively treated patients [32]. Overall, 62 patients were reviewed, of which 33 received further individualized intensive chemotherapy after diagnosis of a second relapse based on the decision of the treating physicians [32]. Eighteen patients (55\%) achieved a third complete remission, indicating that intensive chemotherapy after a second relapse might lead to a medium-term survival benefit in adults [32]. Still, this analysis is limited by the single-center design. In addition, differences in terms of pre-treatment (only 16 patients were previously transplanted) and varying inclusion criteria (such as inclusion of patients with PML-RARA) hinder a comparison with our results [32].

\section{Conclusions}

In summary, despite the fact that this retrospective data collection to our knowledge represents the largest cohort of children with second relapse of AML, the heterogeneous treatment approaches and non-standardized diagnostic time points limit our analysis. However, even with careful consideration of these limitations, this retrospective cohort will help to implement future trial designs and develop relevant endpoints, as until today no population-based data concerning this subgroup of patients had been published.

Supplementary Materials: The following are available online at https:/ / www.mdpi.com/2072-669 4/13/4/789/s1, Table S1: Definitions. Data sharing statement.

Author Contributions: Conceptualization, M.R., E.A.K. and D.R.; methodology, M.R., M.Z. and D.R.; formal analysis, M.Z.; Investigation, M.R., E.A.K., M.Z. and D.R.; resources, M.R., E.S., M.Z., J.-P.B., H.B., I.J., T.L., N.M., N.v.N., N.N., L.S., J.S., C.W., U.C., M.D. and D.R.; writing-original draft preparation, M.R., E.S., E.A.K. and D.R.; writing-review \& editing, all authors; visualization, M.R., M.Z., E.S. and C.W.; supervision, M.R. and D.R.; project administration, M.R.; funding acquisition, M.R. and D.R. All authors have read and agreed to the published version of the manuscript.

Funding: This work was supported by the German Cancer Aid 50-2728, 110244. M.R. is supported by the Josepha und Charlotte von Siebold program.

Institutional Review Board Statement: The study was conducted according to the guidelines of the Declaration of Helsinki, and the retrospective analysis using the data of the patients treated in AML-BFM 2004 and 2012 studies and registry 2012 was performed under the ethical approval of the corresponding Institutional Review Boards of the Ethics Committee of Medical Association Westphalen-Lippe and Medical Faculty of WWU Münster (AML-BFM study 2004: protocol code 3VCreutzig1, 05.06.2003) and the Ethics Committee of Hannover Medical School (AML-BFM registry 2012: protocol code 1381-2012, 13.03.2012; AML-BFM study 2012: 6741M, 20.11.2014).

Informed Consent Statement: Informed consent was obtained from all subjects involved in the study.

Data Availability Statement: The data presented in this study are available on request from the corresponding author. A detailed data sharing statement is provided in Supplementary Materials.

Acknowledgments: The authors would like to thank patients for their participation and the data managers and treating physicians in all hospitals and offices for their efforts in this study.

Conflicts of Interest: D.R. has advisory roles for Celgene Corporation, Novartis, Bluebird Bio, Janssen, and receives research funding from CLS Behring and Roche. J.-P.B. received travel support from Servier. All other authors have nothing to declare. The funders had no role in the design of the study; in the collection, analyses, or interpretation of data; in the writing of the manuscript, or in the decision to publish the results. 


\section{References}

1. Abrahamsson, J.; Forestier, E.; Heldrup, J.; Jahnukainen, K.; Jonsson, O.G.; Lausen, B.; Palle, J.; Zeller, B.; Hasle, H. Responseguided induction therapy in pediatric acute myeloid leukemia with excellent remission rate. J. Clin. Oncol. 2011, 29, 310-315. [CrossRef] [PubMed]

2. Gibson, B.E.; Wheatley, K.; Hann, I.M.; Stevens, R.F.; Webb, D.; Hills, R.K.; De Graaf, S.S.N.; Harrison, C.J. Treatment strategy and long-term results in paediatric patients treated in consecutive, U.K. AML trials. Leukemia 2005, 19, 2130-2138. [CrossRef] [PubMed]

3. Pession, A.; Masetti, R.; Rizzari, C.; Putti, M.C.; Casale, F.; Fagioli, F.; Luciani, M.; Lo Nigro, L.; Menna, G.; Micalizzi, C.; et al. Results of the, A.I.EOP, A.M.L 2002/01 multicenter prospective trial for the treatment of children with acute myeloid leukemia. Blood 2013, 122, 170-178. [CrossRef]

4. Creutzig, U.; Zimmermann, M.; Bourquin, J.P.; Dworzak, M.N.; Fleischhack, G.; Graf, N.; Klingebiel, T.; Kremens, B.; Lehrnbecher, T.; von Neuhoff, C.; et al. Randomized trial comparing liposomal daunorubicin with idarubicin as induction for pediatric acute myeloid leukemia: Results from Study AML-BFM 2004. Blood 2013, 122, 37-43. [CrossRef]

5. Rubnitz, J.E.; Inaba, H.; Dahl, G.; Ribeiro, R.C.; Bowman, W.P.; Taub, J.; Pounds, S.; Razzouk, B.I.; Lacayo, N.J.; Cao, X.; et al. Minimal residual disease-directed therapy for childhood acute myeloid leukaemia: Results of the, A.M.L02 multicentre trial. Lancet Oncol. 2010, 11, 543-552. [CrossRef]

6. Aplenc, R.; Meshinchi, S.; Sung, L.; Alonzo, T.; Choi, J.; Fisher, B.; Gerbing, R.; Hirsch, B.; Horton, T.; Kahwash, S.; et al. Bortezomib with standard chemotherapy for children with acute myeloid leukemia does not improve treatment outcomes: A report from the Children's Oncology Group. Haematologica 2020, 105, 1879. [CrossRef] [PubMed]

7. Rasche, M.; Zimmermann, M.; Borschel, L.; Bourquin, J.P.; Dworzak, M.; Klingebiel, T.; Lehrnbecher, T.; Creutzig, U.; Klusmann, J.H.; Reinhardt, D. Successes and challenges in the treatment of pediatric acute myeloid leukemia: A retrospective analysis of the AML-BFM trials from 1987 to 2012. Leukemia 2018, 32, 2167-2177. [CrossRef]

8. Zwaan, C.M.; Kolb, E.A.; Reinhardt, D.; Abrahamsson, J.; Adachi, S.; Aplenc, R.; De Bont, E.S.; De Moerloose, B.; Dworzak, M.; Gibson, B.E.; et al. Collaborative Efforts Driving Progress in Pediatric Acute Myeloid Leukemia. J. Clin. Oncol. 2015, 33, $2949-2962$. [CrossRef] [PubMed]

9. Creutzig, U.; van den Heuvel-Eibrink, M.M.; Gibson, B.; Dworzak, M.N.; Adachi, S.; de Bont, E.; Harbott, J.; Hasle, H.; Johnston, D.; Kinoshita, A.; et al. Diagnosis and management of acute myeloid leukemia in children and adolescents: Recommendations from an international expert panel. Blood 2012, 120, 3187-3205. [CrossRef] [PubMed]

10. Kaspers, G.J.; Zimmermann, M.; Reinhardt, D.; Gibson, B.E.; Tamminga, R.Y.; Aleinikova, O.; Armendariz, H.; Dworzak, M.; Ha, S.Y.; Hasle, H.; et al. Improved outcome in pediatric relapsed acute myeloid leukemia: Results of a randomized trial on liposomal daunorubicin by the International BFM Study Group. J. Clin. Oncol. 2013, 31, 599-607. [CrossRef]

11. Sander, A.; Zimmermann, M.; Dworzak, M.; Fleischhack, G.; von Neuhoff, C.; Reinhardt, D.; Kaspers, G.J.L.; Creutzig, U. Consequent and intensified relapse therapy improved survival in pediatric, A.M.L: Results of relapse treatment in 379 patients of three consecutive, A.M.L-BFM trials. Leukemia 2010, 24, 1422-1428. [CrossRef]

12. Mustafa, O.; Abdalla, K.; AlAzmi, A.A.; Elimam, N.; Abrar, M.B.; Jastaniah, W. FLAG/FLAG-IDA regimen for children with relapsed/refractory acute leukemia in the era of targeted novel therapies. J. Oncol Pharm Pract. 2019, 25, 1831-1838. [CrossRef] [PubMed]

13. Rubnitz, J.E.; Razzouk, B.I.; Lensing, S.; Pounds, S.; Pui, C.H.; Ribeiro, R.C. Prognostic factors and outcome of recurrence in childhood acute myeloid leukemia. Cancer 2007, 109, 157-163. [CrossRef]

14. Stahnke, K.; Boos, J.; Bender-Gotze, C.; Ritter, J.; Zimmermann, M.; Creutzig, U. Duration of first remission predicts remission rates and long-term survival in children with relapsed acute myelogenous leukemia. Leukemia 1998, 12, 1534-1538. [CrossRef] [PubMed]

15. Webb, D.K.; Wheatley, K.; Harrison, G.; Stevens, R.F.; Hann, I.M. Outcome for children with relapsed acute myeloid leukaemia following initial therapy in the Medical Research Council (MRC) AML 10 trial. MRC Childhood Leukaemia Working Party. Leukemia 1999, 13, 25-31. [CrossRef] [PubMed]

16. Nakayama, H.; Tabuchi, K.; Tawa, A.; Tsukimoto, I.; Tsuchida, M.; Morimoto, A.; Yabe, H.; Horibe, K.; Hanada, R.; Imaizumi, M.; et al. Outcome of children with relapsed acute myeloid leukemia following initial therapy under the, A.M.L99 protocol. Int. J. Hematol. 2014, 100, 171-179. [CrossRef] [PubMed]

17. Karlsson, L.; Forestier, E.; Hasle, H.; Jahnukainen, K.; Jonsson, O.G.; Lausen, B.; Norén Nyström, U.; Palle, J.; Tierens, A.; Zeller, B.; et al. Outcome after intensive reinduction therapy and allogeneic stem cell transplant in paediatric relapsed acute myeloid leukaemia. Br. J. Haematol. 2017, 178, 592-602. [CrossRef] [PubMed]

18. Hoffman, A.E.; Schoonmade, L.J.; Kaspers, G.J. Pediatric relapsed acute myeloid leukemia: A systematic review. Expert Rev. Anticancer Ther. 2020, 1-8. [CrossRef]

19. Abrahamsson, J.; Clausen, N.; Gustafsson, G.; Hovi, L.; Jonmundsson, G.; Zeller, B.; Forestier, E.; Heldrup, J.; Hasle, H.; Nordic Society for Paediatric Haematology and Oncology (NOPHO). Improved outcome after relapse in children with acute myeloid leukaemia. Br. J. Haematol. 2007, 136, 229-236. [CrossRef] [PubMed]

20. Zwaan, C.M.; Reinhardt, D.; Zimmerman, M.; Hasle, H.; Stary, J.; Stark, B.; Dworzak, M.; Creutzig, U.; Kaspers, G.J.L.; International BFM Study Group on Paediatric AML. Salvage treatment for children with refractory first or second relapse of acute myeloid leukaemia with gemtuzumab ozogamicin: Results of a phase, I.I. study. Br. J. Haematol. 2010, 148, 768-776. [CrossRef] 
21. Van Eijkelenburg, N.K.A.; Rasche, M.; Ghazaly, E.; Dworzak, M.N.; Klingebiel, T.; Rossig, C.; Leverger, G.; Stary, J.; De Bont, E.S.; Chitu, D.A.; et al. Clofarabine, high-dose cytarabine and liposomal daunorubicin in pediatric relapsed/refractory acute myeloid leukemia: A phase IB study. Haematologica 2018, 103, 1484-1492. [CrossRef]

22. Aladjidi, N.; Auvrignon, A.; Leblanc, T.; Perel, Y.; Benard, A.; Bordigoni, P.; Gandemer, V.; Thuret, I.; Hugues Dalle, J.; Piguet, C.; et al. Outcome in children with relapsed acute myeloid leukemia after initial treatment with the French Leucemie Aique Myeloide Enfant (LAME) 89/91 protocol of the French Society of Pediatric Hematology and Immunology. J. Clin. Oncol. 2003, 21, 4377-4385. [CrossRef] [PubMed]

23. Wells, R.J.; Adams, M.T.; Alonzo, T.A.; Arceci, R.J.; Buckley, J.; Buxton, A.B.; Dusenbery, K.; Gamis, A.; Masterson, M.; Vik, T.; et al. Mitoxantrone and cytarabine induction, high-dose cytarabine, and etoposide intensification for pediatric patients with relapsed or refractory acute myeloid leukemia: Children's Cancer Group Study 2951. J. Clin. Oncol. 2003, 21, 2940-2947. [CrossRef]

24. Creutzig, U.; Zimmermann, M.; Dworzak, M.N.; Gibson, B.; Tamminga, R.; Abrahamsson, J.; Ha, S.-Y.; Hasle, H.; Maschan, A.; Bertrand, Y.; et al. The prognostic significance of early treatment response in pediatric relapsed acute myeloid leukemia: Results of the international study Relapsed AML 2001/01. Haematologica 2014, 99, 1472-1478. [CrossRef] [PubMed]

25. Goemans, B.F.; Tamminga, R.Y.; Corbijn, C.M.; Hahlen, K.; Kaspers, G.J. Outcome for children with relapsed acute myeloid leukemia in the Netherlands following initial treatment between 1980 and 1998: Survival after chemotherapy only? Haematologica 2008, 93, 1418-1420. [CrossRef]

26. Niewerth, D.; Creutzig, U.; Bierings, M.B.; Kaspers, G.J. A review on allogeneic stem cell transplantation for newly diagnosed pediatric acute myeloid leukemia. Blood 2010, 116, 2205-2214. [CrossRef]

27. Bachas, C.; Schuurhuis, G.J.; Reinhardt, D.; Creutzig, U.; Kwidama, Z.J.; Zwaan, C.M.; van den Heuvel-Eibrink, M.M.; De Bont, E.S.; Elitzur, S.; Rizzari, C.; et al. Clinical relevance of molecular aberrations in paediatric acute myeloid leukaemia at first relapse. Br. J. Haematol. 2014, 166, 902-910. [CrossRef]

28. Sauer, M.G.; Lang, P.J.; Albert, M.H.; Bader, P.; Creutzig, U.; Eyrich, M.; Greil, J.; Gruhn, B.; Holter, W.; Klingebiel, T.; et al. Hematopoietic stem cell transplantation for children with acute myeloid leukemia-results of the AML, SCT-BFM 2007 trial. Leukemia 2020, 34, 613-624. [CrossRef] [PubMed]

29. Karol, S.E.; Alexander, T.B.; Budhraja, A.; Pounds, S.B.; Canavera, K.; Wang, L.; Wolf, J.; Klco, J.M.; Mead, P.E.; Das Gupta, S.; et al. Venetoclax in combination with cytarabine with or without idarubicin in children with relapsed or refractory acute myeloid leukaemia: A phase 1, dose-escalation study. Lancet Oncol. 2020, 21, 551-560. [CrossRef]

30. Bunin, N.J.; Davies, S.M.; Aplenc, R.; Camitta, B.M.; DeSantes, K.B.; Goyal, R.K.; Kapoor, N.; Kernan, N.A.; Rosenthal, J.; Smith, F.O.; et al. Unrelated donor bone marrow transplantation for children with acute myeloid leukemia beyond first remission or refractory to chemotherapy. J. Clin. Oncol. 2008, 26, 4326-4332. [CrossRef]

31. Nishikawa, T.; Inagaki, J.; Nagatoshi, Y.; Fukano, R.; Nakashima, K.; Ito, N.; Sawa, D.; Kawano, Y.; Okamura, J. The second therapeutic trial for children with hematological malignancies who relapsed after their first allogeneic, S.C.T: Long-term outcomes. Pediatr. Transplant. 2012, 16, 722-728. [CrossRef] [PubMed]

32. Stoiser, B.; Knobl, P.; Fonatsch, C.; Haas, O.A.; Mitterbauer, G.; Weltermann, A.; Geissler, K.; Valent, P.; Sperr, W.; Pabinger, I.; et al. Prognosis of patients with a second relapse of acute myeloid leukemia. Leukemia 2000, 14, 2059-2063. [CrossRef] [PubMed] 